\section{BUPRENORPHINE INFUSION IN THE PRETERM NEWBORN}

Queen's Medical Centre, Nottingham and Deparment of Pharm, City Hospital and Nottingham, UK.

Introduction: Buprenorphinc is an opiate analgesic used in adults, children and in the newborn.

Aims of study: Investigation of the pharmacokinetics and pharmacodynanics of buprenorphine in the preterm newborn. This has not been studied previously.

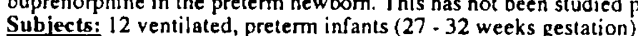

Intervention: Buprenorphine administration as a loading dose $(3 \mathrm{mcg} / \mathrm{kg})$ and Intervention: Buprenorphine adminis

Measurements: Serial blood samples for buprenorphine concentration, blood gases
Mentinuous infusion $(.72 \mathrm{mcg} / \mathrm{kg} / \mathrm{hr})$ Measurements: Serial blood samples for buprenorphine concentration, blood gase Results:There were significant $(p<0.05)$ falls in heart rate and systolic blood pressure from baseline values during buprenorphine infusion. Mean(SD) steady state buprenorphine concentration was $3.6(1.8) \mathrm{ng} / \mathrm{ml}$. Mcan(SD) clearance of buprenorphine was $4.3(1.8) \mathrm{ml} / \mathrm{min} / \mathrm{kg}$ and terminal half-life in excess of 24 hours. Four infants required an increase in the buprenorphine infusion rate and one infant was withdrawn because of inadequate sedation.

Conclusions (1) Buprenophine infusion in this age group showed increased steady state concentration. reduced clearance and prolonged half-life compared to older children and adults. (2) Buprenorphine in the pre-term newborn appears to be safe but not always effective. (3) There is a non-standard relationship between the phamacolegical effect and plasma drug concentration which makes buprenorphinte inappropriate for use in neonatal intensive carc.
120

NATURAL SURFACTANT (SF) VS. BRIEF LIQUID VENTILATION (LV) RESCUE THERAPY IN VERY IMMATURE IAMBS. AdOIf Valls-iSoler*, Marla wolfson, Thomas Shaffer. spn. by Juan $R$ Soriano*. Temple Univer. Dept. Physiol-Pediat. Philadelphia USA and (*) Dept. Pediat, Basque Univer. Bilbao,spain. In 1 mmature lambs prophylactic LV provides better gas matched lambs (gest=1litld), after GV for first $45 \mathrm{~min}$ of life, lambs were rescued: G-I $(\mathrm{n}=6)$ with $200 \mathrm{mg} / \mathrm{Kg}$ of $14 \mathrm{C}$ -DPPC label SF (Curosurf) and $G-I I(n=6)$ with brief ( $5 \mathrm{~min}$ ) compared to previous studies in lambs with iv (G-III;n=7) and GV (G-IV;n=9) since birth (J.Appl. Physiol. 72:1024; 1992). Oxygenation improved after therapy in both rescue groups, not reaching G-III levels. In G-II paO2 decrease need to be increased to values above those of G and PEEP both G-I and II pulmonary compliance similarly increased after rescure and compared to untreated lambs, been less than in G-III. Labeled SF was distributed with $>658$ of lung sections with an amount within 208 of mean. Bleeding through tracheal tube was seen in $5 / 8$ lambs in $G-I$ immediately after treatment and was not seen in other groups. Gross and microscopic examination of lungs demonstrated evidence of hemmorhage and uneven inflation in all groups but G-III. Even in very imature lambs, both rescue strategies transiently improve gas exchange and pulmonary function: although exposure of imature lung to GV after rescue, impedes a sustalned effect of both rescue modali-

\section{1}

SUREACTANT PROTEIN A (SI'-A) AND INILAMMATORY CIIANGISS IN TRACIIEA! ASPIRATES FRON VENTILATED NEWDORN INI ANTS, SLCFUII

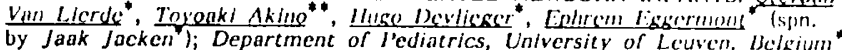
by Jaak Jacken ); Department of l'ediatrics, University of Leuven. Bclgium and Department of Biochemistry, Sapporo Medical College, Japan". Bronchopulmonary dysplasla (BP'D) following respiratory distress syndrome
(RDS) has been correlated with persistent surfuctant deficiency, is prolonged neutrophil influx and a decreased macrophage response in tracheal aspirate contents during the second half of the first week. These variables have not been studied comparing mild (type 1) and severe (type 2) forms of BPD. W' prospectively measured SP-A, proteln concentration neuerophit and BP. We phage counts in 376 tracheal asplrate samples of 105 consecutively ventilated newborn infants in a longitudinal fashlon. Fifty-eight patients had RDS (group A), 28 had pulmonary discases other than RDS (group B) and 19 had no lung disease (group C). At day L, RDS patients had lower levels of SP$A$, protein, neutrophil and macrophage counts han infants of groups $B$ a C. prong increase in tracheal SP-A concentration, neutrophil and associated with an increase ln tracheal SP-A concentration, neutrophil and macrophage count In SP-A willout a cociated with an increas In SP-A whent a cellular hilux, und 'poor oulcome' (tyse 2 IBI'l) or survival at day 28) was assoclated with nelther SP-A increase nor inflammatory response. Our lindings confirm that a sustained increase in tracheal surfactant concentration and macrophage count is associated with RDS survival without BPD. However, contrary to current understanding, it is suggested that cure of RDS also requires a neutrophil inflammatory response, which Is absent in type 1 and type 2 BPD patients and nonsurvivors. The latter two also fall to produce surfactant. Early treatment with corticosterolds may therefore not be appropriate for these infants.
ASPIRIN VERSUS INDOMETHACINE TREATMENT OF PATENT DUCTUS ARTERIOSUS (PDA) IN THE PRETERM NEONATE WITH RESPIRATORY DISTRESS SYNDROME (RDS), Bart Van Overmeire*, Frank Brua**, Nynke J.Elzenga*", Albert Okken**. Departmente Of Pedlatrics, University Hospitale of

Indomethacine (Indo) $1 \mathrm{~s}$ commonly ueed for treatment of PDA, it main ide effect 1 s renal fallure. Asplín (ASA) lo an alternative but there are no controlled triala on ito efflcacy. We randomly asGigned 75 premature Infenta buffering from RDS (mean GA: $29.6 \pm 2.5$ wks, mean BW: $1295 \pm 464 \mathrm{gr}$ ) on artiflctal ventilation at atart of study (mean : 3.4 day of $11 \mathrm{fe}$ ), to olther Indo $(3 \times 0.2 \mathrm{mg} / \mathrm{kg} / 12 \mathrm{hrs}$ ) or ASA $(4 \times 15 \mathrm{mg} / \mathrm{kg} / 6 \mathrm{hrs})$. PDA and degree of shunting were diagnosed by echocardlo-Doppler at start and after 2 and 4 days. Side effects, eapecially diminution of diuresis, were carefully recorded. Results: PDA closed in $35 / 38$ patlente from the Indo group 193 . and in $16 / 37$ patiente from the ASA group $(43$ I) ( $p<0.001)$. No reopenlnge were obgerved in both groupg. 19 patienta needed further treatment with Indo or surgery $(17$ in the ASA group and 2 in the Indo groupl. No side effects were seen in both groupa except for a decresse of diureais in the Indogroup during 4 postreatment days (difference on 2 nd posttreatment day: indo $\mathrm{m} 1 \mathrm{nus} 1.06 \mathrm{ml} / \mathrm{kg} / \mathrm{h}$ ve ASA: plua $0.48 \mathrm{ml} / \mathrm{kg} / \mathrm{h} ; \mathrm{p}<0.01)$. Fluld management was not different between both groupg. Closing of PDA was positively correlated with $G A$, but not with time of etarting Indo/ASA or grade of ehunting. ConclusioniAsA is not as offective in cloaing PDA as Indo, but has no adverse offect on diuresis.

\section{3}

ROLE OF ALLOPURINOL IN REDUCING CEREBRAL HYPOXIC-ISCHEMIC INJUR DURING REOXYGENATION-REPERFUSION. Paul Y $K W^{\prime} u$. W'on $S$ Park Frans $F$ JobsisVanderilics. USC Sch of Med. LAC+USC Med CIt, Div of Nconatologs, Depl of Pediatrics, Los Angeics, and Duke Univ., Dept of Cell Biology, Durham, N.C. U.S A

Oxidation of hypoxanthine $(\mathrm{HX})$ by xanthine oxidase $(\mathrm{XO})$ has been hypothesı/ced 10 be a polentua source of oxygen-derived frec radicles $\left(\mathrm{O}_{2}^{\circ}\right)$ during reoxygenation-perfusion of hypovic-ischentic organs. Allopurinol (Al), a XO inhibilor, can reduce reperfusion injury. During hypovia-ischemia components of the milochondrial electron-transport chain become reduced With reorygenationreperfusion $\mathrm{O}_{2}{ }^{-}$are gencrated. A Ncar Infrared Spectroscope (Niroscope) was uscd to continuously monitor changes in cylochrome aa ${ }_{3}$ (C) taa $)$, blood volume (BV), saturated $\mathrm{Hb}$ (HbO) and desalurated (JI8-) in 24 rats. The rats were divided inlo 2 groups (Gp). Gpl (12), Wl $=286+38 \mathrm{~g}(\mathrm{~m}+\mathrm{SD})$ reccirc $\mathrm{Al}$ (dosc $200 \mathrm{mg} / \mathrm{kg} \mathrm{IP}$ ) and was subjected to $1 / 2 \mathrm{hr}$ period of $9.7 \% \mathrm{O}_{2}$ followed by $100 \% \mathrm{O}_{2}$ Gil2 (12). Wl $282 \pm 4 \mathrm{ig}\left(\mathrm{m} \pm \mathrm{SD}\right.$ ) was subjected 10 the same 2 periods of $\mathrm{F}_{1} \mathrm{O}_{2}$ but without prior $\mathrm{Al}$ Results:

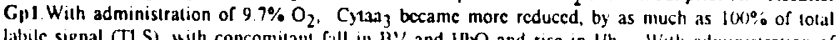
labile signal (TLS), with concomilani fall in BV and $\mathrm{IJOO}$ and risc in Ifb. Will admunstration of $100 \% \mathrm{O}_{2}$. Cytaa becante morc oxidizcd with concomitant rise in $\mathrm{BV}$ and $1 \mathrm{bb}$ and fall in $/ \mathrm{lb}$. G $\mathrm{G}_{\mathrm{p}} 2$ During the hypovic period $\left(9.7 \% \mathrm{O}_{2}\right)$ the clianges in $\mathrm{Cy}_{1 \mathrm{aa}}$. BV, $1 \mathrm{HbO}$ and $\mathrm{Hb}$ - were similar to those oblaincd in Gpl. However on reongenation with $100 \% \mathrm{O}_{2}$ the Cytaa remained reduced despite increases in $\mathrm{BV}$ and $\mathrm{HbO}$ and $\mathrm{fall}$ in $\mathrm{Hb}$. To craluatc the rols of $\mathrm{Bl}$ and $\mathrm{XO}$ in these changes an additional 6 rats on $100 \% \mathrm{O}_{2}$ were infused with I. HX (dose calculated to provide a plasmia additional 6 rats on $100 \% \mathrm{O}_{2}$ werc infused with $\mathrm{I}$. IXX (dose calculatcd to provide a plasnia Infusion of IIX, and XO, with of without arabinose, did not of $1.6 \mathrm{M}$ Sol) 3 . $11 \mathrm{X}+\mathrm{XO}$ (1 unit) icsulis suggest that allopurinol protect the milochondrial cectron-transport chian from $\mathrm{O}_{2}{ }^{\circ}$ during

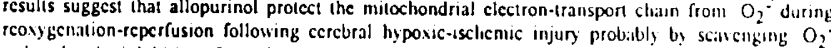
rather tl "l by inhbibition of xinthinc oxidase.

\section{4}

CEREBRAL DOPPLER CAN SERIOUSLY MISREPRESENT FLOW CHANGES. Marianne Thoresen" and Kirsti Haaland", (spn by Andrew Whitelaw) Dept. of Experimental Medical Research, University of Oslo, Ullevâl Hospital and "Depl of Pediatric Research, Rikshospitalet, Osto.

Doppler ultrasound has been widely used to investigate the mechanisms of cerebral ischaemia in sick newborns. If the diameter of the vessel is constant, then changes in cerebral blood flow velocity (CBFV) reflect tue changes in volume flow. Even if vessel diameter increases by distention under increased pressure, it is widely assumed that the changes in CBFV will be in the same direction as true changes in flow

4 newborn piglets underwent simultaneous measurements of cerebral blood flow by electromagnetic flowmetry (EM) on the common carotid artery (extracerebral branches were ligated) and Doppler CBFV. The two methods agreed well under normal conditions ie within moderate $\mathrm{CO} 2$ and blood pressure changes. Pathological changes were induced by infusion of $6-11$ $\mathrm{m} / \mathrm{kg}$ of a) blood which had boen infected b) blood which was incompatible (human) $\mathrm{C}$ ) blood which was chilled to $4^{\circ} \mathrm{C}$ d) blood heated to $45.50^{\circ} \mathrm{C}$. Incompatible blood resulted in a $75 \%$ increase in EM CBF but only $10 \%$ increase in Doppler CBFV. Cooled blood gave Doppler changes that were greater than the EM changes and heated blood gave Doppler changes that were smaller than the EM changes. Intected blood resulted in a decrease in Doppler CBFV of $50 \%$ while the EM CBF increased by $30 \%$

These lindings could be explained by vasoactive substances changing the diameters of large arteries. It is theretore possible that Doppler CBFV measurements in critically ill infants with eg sepsis might be misleading. 